\title{
Roseomonas lacus sp. nov., isolated from freshwater lake sediment
}

\author{
Cheng-Ying Jiang, Xin Dai, Bao-Jun Wang, Yu-Guang Zhou \\ and Shuang-Jiang Liu
}

Correspondence

Shuang-Jiang Liu

shuangjiang@hotmail.com
State Key Laboratory of Microbial Resources, Institute of Microbiology, Chinese Academy of
Sciences, Zhong-Guan-Cun, Haidian, Beijing 100080, P. R. China

An aerobic, Gram-negative bacterial strain, $\mathrm{TH}-\mathrm{G} 33^{\top}$, was isolated from freshwater sediment of Taihu Lake in China. The taxonomy of strain $\mathrm{TH}-\mathrm{G}_{3} 3^{\top}$ was studied by using phenotypic and phylogenetic methods. Cells of strain $\mathrm{TH}-\mathrm{G} 33^{\top}$ were coccoid rods or rods and formed colourless to pale-pink colonies on nutrient agar. Phylogenetic analysis based on nearly complete 16S rRNA gene sequences showed that strain $\mathrm{TH}-\mathrm{G} 33^{\top}$ was related to Roseomonas mucosa (94.4\%), Roseomonas gilardii subsp. gilardii (94.1\%), Roseomonas gilardii subsp. rosea (94.8\%) and Roseomonas cervicalis (93.9\%). Cells contained ubiquinone $10(\mathrm{Q}-10)$ as the major quinone and the $\mathrm{G}+\mathrm{C}$ content was $71.9 \mathrm{~mol} \%$. Thus, strain $\mathrm{TH}-\mathrm{G}_{3}{ }^{\top}$ represents a novel species of the genus Roseomonas, for which the name Roseomonas lacus sp. nov. is proposed. The type strain is TH-G33 ${ }^{\top}\left(=\right.$ CGMCC $\left.1.3617^{\top}=\mathrm{JCM} 13283^{\top}\right)$.
The genus Roseomonas (Rihs et al., 1993) was created for pink coccoid isolates that caused bacteraemia and other human infections. Roseomonas species have been isolated frequently from blood, wounds, exudates, abscesses and genitourinary specimens (Rihs et al., 1993; Sandoe et al., 1997; Bibashi et al., 2000; Subudhi et al., 2001). Recently, bacterial strains that are phylogenetically related to members of the genus Roseomonas have also been isolated frequently from environmental samples such as drinking water distribution systems (September et al., 2004), oil wells (Roseomonas strain BON 1; GenBank accession no. AY219712), biological soil crust (Roseomonas strain CP4B2; AJ871456), agriculture drainage water (Roseomonas strain SA-2; AY730026), as well as from water (Rihs et al., 1993). Roseomonas-related 16S rRNA gene sequences have also been detected frequently during molecular surveys of microbial diversity in various environments, for example, in the freshwater bacterial communities associated with cyanobacterial blooms in four Swedish lakes (Eiler \& Bertilsson, 2004). All these facts indicate that members of the genus Roseomonas could occur widely in nature. However, no names of environmental isolates (non-medical source) of Roseomonas have been validly published. Currently, all members of the genus Roseomonas with validly published names, including Roseomonas cervicalis,

Published online ahead of print on 19 August 2005 as DOI 10.1099/ ijs.0.63938-0.

The GenBank/EMBL/DDBJ accession number for the 16S rRNA gene sequence of Roseomonas lacus TH-G33 ${ }^{\top}$ is AJ786000.

A table showing the cellular fatty acid profile of Roseomonas lacus $\mathrm{TH}-$ G33 $^{\top}$ is available as supplementary material in IJSEM Online.
Roseomonas fauriae, Roseomonas gilardii subsp. gilardii (Rihs et al., 1993), Roseomonas gilardii subsp. rosea and Roseomonas mucosa (Han et al., 2003), were isolated from medical samples.

Strain TH-G33 ${ }^{\mathrm{T}}$ was isolated from sediment of the freshwater Taihu Lake (also called lake Tai; $120^{\circ} 02^{\prime} 16 \cdot 8^{\prime \prime} \mathrm{E} 31^{\circ}$ $27^{\prime} 10 \cdot 7^{\prime \prime} \mathrm{N}$, Jiangsu Province, China), by plating 10 -fold dilutions of samples on dilute nutrient medium (DNM) containing $\left(1^{-1}\right): 0 \cdot 3 \mathrm{~g}$ beef extract, $1.0 \mathrm{~g}$ fish peptone, $0 \cdot 1 \mathrm{~g}$ yeast extract, $0.5 \mathrm{~g} \mathrm{NaCl}$ and $15 \mathrm{~g}$ agar. Sediment samples were obtained from $10 \mathrm{~cm}$ beneath the sediment surface. LB or nutrient medium (NM) agar or broth at $30{ }^{\circ} \mathrm{C}$ were used for routine cultivation.

Gram reactions were determined by staining cells grown on $\mathrm{NM}$ agar at $30^{\circ} \mathrm{C}$ for $24 \mathrm{~h}$ according to the method described by Gerhardt et al. (1994). Endospore formation was determined after malachite green staining of cells grown on LB agar. Cell flagellation and morphology were examined by using transmission and scanning electron microscopy. For assimilation of carbon sources, the standard mineral base solution of Stanier et al. (1966) was used. Each compound was added at a concentration of $0 \cdot 2 \%(\mathrm{w} / \mathrm{v})$ after the mineral base solution had been autoclaved. Growth was examined after incubation at $30{ }^{\circ} \mathrm{C}$ for $1,3,7$ and 14 days. Aerobic and anaerobic production of acid (O-F reaction) from carbohydrates was determined using $\mathrm{O}-\mathrm{F}$ basal medium (Hugh \& Leifson, 1953). Carbohydrate solutions sterilized by filtration were added at a final concentration of $1 \%(\mathrm{w} / \mathrm{v})$ and acid production was recorded after 7 and 14 days of incubation. For cellular fatty acid analysis, strains were grown for $72 \mathrm{~h}$ at $30^{\circ} \mathrm{C}$ on $\mathrm{NM}$ agar. Cells were 
harvested from the plates and saponified, and the liberated fatty acids were methylated and analysed by using the Sherlock system (Microbial ID Inc.), following the manufacturer's instructions. Isoprenoid quinones were extracted from freeze-dried cells $(200 \mathrm{mg}$ ) with methyl chloride/ methanol $(2: 1)$ and analysed by reversed-phase HPLC. The sensitivity to various antibiotics was tested by using the disc diffusion method (Kirby-Bauer method).

The DNA base composition was determined by thermal denaturation (Marmur \& Doty, 1962) using DNA from Escherichia coli DH-5 $\alpha$ as a control. The $16 \mathrm{~S}$ rRNA gene was amplified as described previously (Zhang et al., 2003) and $16 \mathrm{~S}$ rRNA gene sequence alignments were performed with the CLUSTAL_X program (version 1.64b; Thompson et al., 1997). The phylogenetic tree was constructed by using the neighbour-joining method (Saitou \& Nei, 1987) with Kimura's two-parameter calculation model in TREECON W version $1.3 \mathrm{~b}$.

Cells of strain $\mathrm{TH}-\mathrm{G} 33^{\mathrm{T}}$ were Gram-negative, aerobic, non-spore-forming coccoid rods or rods (Fig. 1). Flagella were not observed. Growth occurred at $15-40{ }^{\circ} \mathrm{C}$ and $\mathrm{pH} 6 \cdot 0-9 \cdot 0$, with optima at $30^{\circ} \mathrm{C}$ and $\mathrm{pH} 7 \cdot 0$. Cultures grown in NM broth were colourless. Colonies on NM agar were colourless to pale-pink. Colonies were pinpoint, raised, entire, runny and mucoid, with a diameter of $0 \cdot 5-1 \cdot 0 \mathrm{~mm}$ after incubation for 3-4 days. Catalase and oxidase reactions were positive. $16 \mathrm{~S}$ rRNA gene sequence analysis showed that strain TH-G33 ${ }^{\mathrm{T}}$ was phylogenetically related to members of the genus Roseomonas (similarities $93 \cdot 2-94 \cdot 8 \%$ ), with the greatest similarity to $R$. gilardii subsp. rosea $(94 \cdot 8 \%)$ followed by $R$. mucosa $(94 \cdot 4 \%)$. A neighbour-joining tree based on these 16S rRNA gene sequences was constructed (Fig. 2), which showed that strain TH-G33 ${ }^{\mathrm{T}}$ and other species of the genus Roseomonas except $R$. fauriae, which has been suggested not to be a member of the genus Roseomonas (Cohen et al., 2004; Han et al., 2003), were grouped together. Thus, strain TH-G33 ${ }^{\mathrm{T}}$ represents a novel species of the genus Roseomonas.
Phenotypic properties, such as assimilation of sugars and other carbon sources, hydrolysis of complex organic compounds and reduction of nitrate, were determined. The results are included in the species description. In conclusion, strain TH-G33 ${ }^{\mathrm{T}}$ was shown to be a unique isolate from freshwater sediment and could be differentiated from other species of Roseomonas by a range of features. Strain TH$\mathrm{G} 33^{\mathrm{T}}$ did not have flagella, grew in $\mathrm{NaCl}$ at concentrations up to $6.5 \%$ and had an optimum growth temperature of $30^{\circ} \mathrm{C}$. Unlike $R . m u c o s a$, strain $\mathrm{TH}-\mathrm{G} 33^{\mathrm{T}}$ reduced nitrate, but did not assimilate D-glucose or citrate. Some properties that differentiate species of Roseomonas are given in Table 1. The major cellular fatty acids of strain $\mathrm{TH}-\mathrm{G} 33^{\mathrm{T}}$ were iso- $\mathrm{C}_{15: 0}(19 \cdot 9 \%)$, iso- $\mathrm{C}_{16: 0}(38 \%)$ and iso- $\mathrm{C}_{17: 1} \omega 9 c$ $(12 \cdot 1 \%)$. The cellular fatty acid profile of strain $\mathrm{TH}-$ $\mathrm{G}^{\mathrm{T}}{ }^{\mathrm{T}}$ (Supplementary Table in IJSEM Online) was also significantly different from those reported for $R$. mucosa, $R$. gilardii, R. cervicalis and R. fauriae. Strain TH-G33 ${ }^{\mathrm{T}}$ was susceptible to ampicillin, piperacillin, amoxicillin, piperacillin/tazobactam, cefazolin, cephalothin, cefuroxime, cefotaxime, cefaclor, cefoperazone, ceftazidime, amikacin, gentamicin, tobramycin, kanamycin, streptomycin, tetracycline, doxycycline, minocycline, ciprofloxacin, levofloxacin, norfloxacin, lomefloxacin, fleroxacin, erythromycin, nitrofurantoin, polymyxin and chloramphenicol, but not to trimethoprim/sulfamethoxazole or enoxacin.

These results suggest that strain $\mathrm{TH}-\mathrm{G} 33^{\mathrm{T}}$ represents a novel aquatic species, for which we propose the name Roseomonas lacus sp. nov.

\section{Description of Roseomonas lacus sp. nov.}

Roseomonas lacus (la'cus. L. masc. gen. n. lacus of a lake, indicating the site of isolation of this organism).

Cells are coccoid rods or rods, $0 \cdot 5-0 \cdot 8 \times 0 \cdot 8-1 \cdot 5 \mu \mathrm{m}$. Non-motile, without flagella. Gram-negative. Colonies on NM or DNM agar are circular, raised, entire, runny and mucoid, colourless to pale-pink and $0.5-1 \cdot 0 \mathrm{~mm}$ in
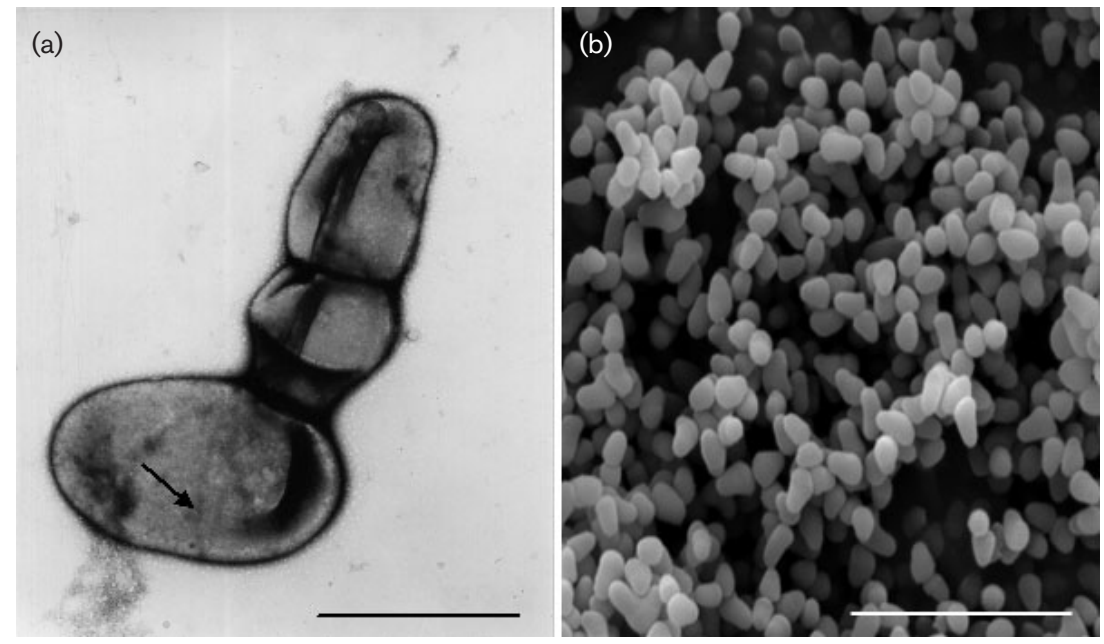

Fig. 1. Transmission (a) and scanning (b) electron micrographs showing the morphology of Roseomonas lacus sp. nov. strain $\mathrm{TH}-\mathrm{G} 33^{\top}$. The dark ring (arrow) in (a) indicates the position at which the cell may divide. Bars, $1 \mu \mathrm{m}$ (a) and $5 \mu \mathrm{m}$ (b). 


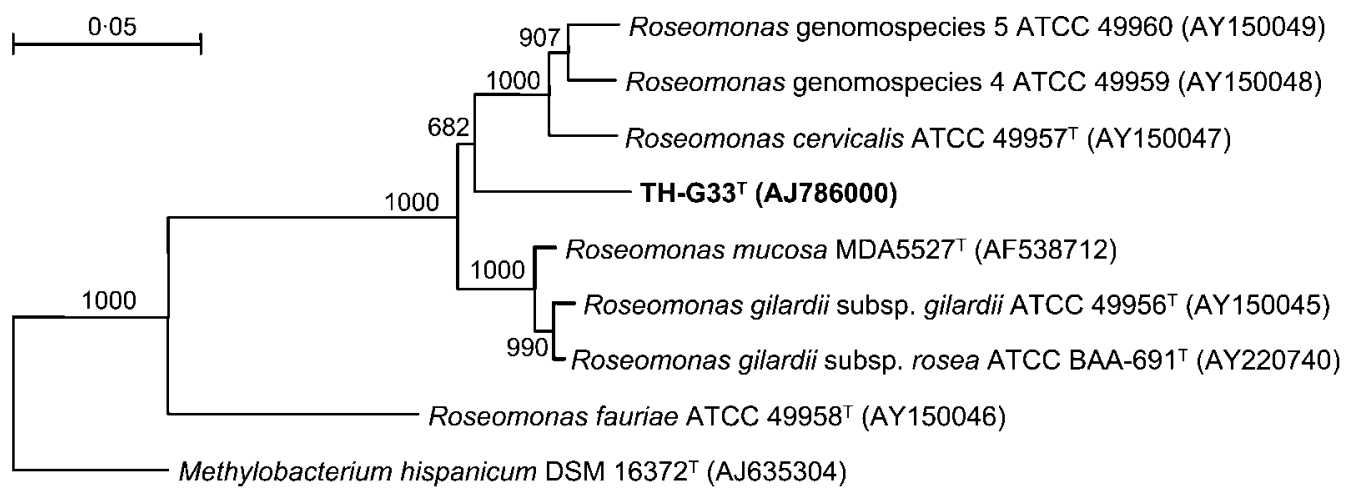

Fig. 2. Phylogenetic tree constructed using the neighbour-joining method based on $16 \mathrm{~S}$ rRNA gene sequences of strain $\mathrm{TH}_{-\mathrm{G} 33^{\top}}$ and related bacteria. Numbers at nodes indicate bootstrap support based on 1000 resampled datasets. Methylobacterium hispanicum was used as the outgroup. Bar, evolutionary distance $\left(K_{\text {nuc }}\right)$ of $0 \cdot 05 . R$. fauriae is out of the Roseomonas group and most probably represents a member of a different bacterial genus, as also proposed by others (Cohen et al., 2004; Han et al., 2003).

diameter after incubation for $3-4$ days. Grows at $15-40{ }^{\circ} \mathrm{C}$ and $\mathrm{pH} 6 \cdot 0-9 \cdot 0$, with optima at $30^{\circ} \mathrm{C}$ and $\mathrm{pH} 7 \cdot 0$. Oxidaseand catalase-positive. Grows in $\mathrm{NaCl}$ at concentrations up to $6.5 \%$. Nitrate is reduced. Casein, gelatin, starch, Tween 80 and aesculin are not hydrolysed. Voges-Proskauer test and methyl red reaction are negative. Oxidizes ribose, Lrhamnose, D-galactose, L-arabinose, DL-sorbose, fucose,

Table 1. Characteristics that differentiate between members of the genus Roseomonas

Taxa: 1, strain TH-G33 ${ }^{\mathrm{T}} ; 2$, R. mucosa; 3, R. gilardii; 4, R. cervicalis; $5, R$. fauriae. Data for $R$. mucosa, R. gilardii, R. cervicalis and $R$. fauriae from Han et al. (2003), Rihs et al. (1993) and Wallace et al. (1990). +, Positive; -, negative; V, variable; ND, not determined.

\begin{tabular}{|lccccc|}
\hline Characteristic & $\mathbf{1}$ & $\mathbf{2}$ & $\mathbf{3}$ & $\mathbf{4}$ & $\mathbf{5}$ \\
\hline Flagellum & - & + & + & + & + \\
Motility & - & + & - & + & + \\
Reduction of $\mathrm{NO}_{3}^{+}$ & + & - & $\mathrm{V}$ & - & + \\
$\mathrm{H}_{2}$ S production & $\mathrm{ND}$ & $\mathrm{ND}$ & - & - & - \\
Indole production & $\mathrm{ND}$ & - & - & - & - \\
Hydrolysis of aesculin & - & - & - & - & + \\
Gelatin liquefaction & - & $\mathrm{ND}$ & - & - & - \\
Utilization of carbon compounds: & & & & & \\
$\quad$ D-Glucose & - & + & $\mathrm{V}$ & - & $\mathrm{V}$ \\
$\quad$ Fructose & - & - & + & + & + \\
$\quad$ Ribose & + & $\mathrm{ND}$ & $\mathrm{ND}$ & $\mathrm{ND}$ & $\mathrm{ND}$ \\
$\quad$ D-Galactose & + & $\mathrm{ND}$ & $\mathrm{V}$ & - & + \\
L-Arabinose & + & + & $\mathrm{V}$ & $\mathrm{V}$ & + \\
D-Xylose & + & $\mathrm{ND}$ & $\mathrm{V}$ & $\mathrm{V}$ & + \\
D-Mannitol & - & $\mathrm{ND}$ & $\mathrm{V}$ & - & - \\
Glycerol & - & $\mathrm{ND}$ & + & - & + \\
Citrate & - & + & + & $\mathrm{V}$ & $\mathrm{V}$ \\
Optimum growth temperature $\left({ }^{\circ} \mathrm{C}\right)$ & 30 & 35 & 35 & 35 & 35 \\
& & & & & \\
\hline
\end{tabular}

sucrose, D-cellobiose, D-melibiose and D-xylose. Does not utilize D-glucose, fructose, DL-sorbitol, DL-raffinose, DLlactose, L-lysine, D-mannitol, acetate, propionate, glycerol or citrate. The major quinone is ubiquinone $10(\mathrm{Q}-10)$. The major cellular fatty acids $(>1 \%)$ are iso- $\mathrm{C}_{14: 0}(5 \cdot 8 \%)$, iso$\mathrm{C}_{15: 0}(19 \cdot 9 \%)$, iso- $\mathrm{C}_{15: 1}(1 \cdot 6 \%)$, anteiso- $\mathrm{C}_{15: 0}(4 \cdot 3 \%)$, $\mathrm{C}_{15: 0}(1 \cdot 5 \%)$, iso- $\mathrm{C}_{16: 0}(38 \%)$, iso- $\mathrm{C}_{16: 1}(5 \cdot 0 \%), \mathrm{C}_{16: 0}$ $(1 \cdot 9 \%)$, iso- $\mathrm{C}_{17: 0}(4 \%)$, anteiso- $\mathrm{C}_{17: 0}(2 \cdot 1 \%)$ and iso$\mathrm{C}_{17: 1} \omega 9 c(12 \cdot 1 \%)$. Sensitive to a range of antibiotics but not to trimethoprim/sulfamethoxazole or enoxacin.

The type strain, TH-G33 ${ }^{\mathrm{T}}$ (=CGMCC $1.3617^{\mathrm{T}}=\mathrm{JCM}$ $\left.13283^{\mathrm{T}}\right)$, was isolated from freshwater lake sediment. The $\mathrm{G}+\mathrm{C}$ content of the type strain is $71.9 \mathrm{~mol} \%$.

\section{Acknowledgements}

This work was supported by grants from the Chinese Academy of Sciences (KJCX1-SW-12-II-02-02) and from the Natural Science Foundation of China (20177034).

\section{References}

Bibashi, E., Sofianou, D., Kontopoulou, K., Mitsopoulos, E. \& Kokolina, E. (2000). Peritonitis due to Roseomonas fauriae in a patient undergoing continuous ambulatory peritoneal dialysis. J Clin Microbiol 38, 456-457.

Cohen, M. F., Han, X. Y. \& Mazzola, M. (2004). Molecular and physiological comparison of Azospirillum spp. isolated from Rhizoctonia solani mycelia, wheat rhizosphere, and human skin wounds. Can J Microbiol 50, 291-297.

Eiler, A. \& Bertilsson, S. (2004). Composition of freshwater bacterial communities associated with cyanobacterial blooms in four Swedish lakes. Environ Microbiol 6, 1228-1243.

Gerhardt, P., Murray, R. G. E., Wood, W. A. \& Krieg, N. R. (1994). Methods for General and Molecular Bacteriology. Washington, DC: American Society for Microbiology. 
Han, X. Y., Pham, A. S., Tarrand, J. J., Rolston, K. V., Helsel, L. O. \& Levett, P. N. (2003). Bacteriologic characterization of 36 strains of Roseomonas species and proposal of Roseomonas mucosa sp nov and Roseomonas gilardii subsp rosea subsp nov. Am J Clin Pathol 120, 256-264.

Hugh, R. \& Leifson, E. (1953). The taxonomic significance of fermentative versus oxidative metabolism of carbohydrates by various Gram negative bacteria. J Bacteriol 66, 24-26.

Marmur, J. \& Doty, P. (1962). Determination of the base composition of deoxyribonucleic acid from its thermal denaturation temperature. J Mol Biol 5, 109-118.

Rihs, J. D., Brenner, D. J., Weaver, R. E., Steigerwalt, A. G., Hollis, D. G. \& Yu, V. L. (1993). Roseomonas, a new genus associated with bacteremia and other human infections. J Clin Microbiol 31, 3275-3283.

Saitou, N. \& Nei, M. (1987). The neighbor-joining method: a new method for reconstructing phylogenetic trees. Mol Biol Evol 4, 406-425.

Sandoe, J. A. T., Malnick, H. \& Loudon, K. W. (1997). A case of peritonitis caused by Roseomonas gilardii in a patient undergoing continuous ambulatory peritoneal dialysis. J Clin Microbiol 35, 2150-2152.
September, S. M., Brozel, V. S. \& Venter, S. N. (2004). Diversity of nontuberculoid Mycobacterium species in biofilms of urban and semiurban drinking water distribution systems. Appl Environ Microbiol 70, 7571-7573.

Stanier, R. Y., Palleroni, N. J. \& Doudoroff, M. (1966). The aerobic pseudomonads: a taxonomic study. J Gen Microbiol 43, 159-271.

Subudhi, C. P. K., Adedeji, A., Kaufmann, M. E., Lucas, G. S. \& Kerr, J. R. (2001). Fatal Roseomonas gilardii bacteremia in a patient with refractory blast crisis of chronic myeloid leukemia. Clin Microbiol Infect 7, 573-575.

Thompson, J. D., Gibson, T. J., Plewniak, F., Jeanmougin, F. \& Higgins, D. G. (1997). The CLUSTAL_X Windows interface: flexible strategies for multiple sequence alignment aided by quality analysis tools. Nucleic Acids Res 25, 4876-4882.

Wallace, P. L., Hollis, D. G., Weaver, R. E. \& Moss, C. W. (1990). Biochemical and chemical characterization of pink-pigmented oxidative bacteria. J Clin Microbiol 28, 689-693.

Zhang, D., Yang, H., Zhang, W., Huang, Z. \& Liu, S.-J. (2003). Rhodocista pekingensis sp. nov., a cyst-forming phototrophic bacterium from a municipal wastewater treatment plant. Int J Syst Evol Microbiol 53, 1111-1114. 